\title{
CONTRIBUIÇÕES DE UM GRUPO DE PESQUISA NA PRODUÇÃO CIENTÍFICA EM EDUCAÇÃO INCLUSIVA NA REGIÃO AMAZÔNICA
}

\author{
CONTRIBUTIONS OF A GROUP OF SCIENTIFIC RESEARCH IN \\ PRODUCTION IN INCLUSIVE EDUCATION IN THE AMAZON REGION
}

Samuel Vinente Silva Junior ${ }^{1}$ e Ketlen Júlia Lima Da Silva ${ }^{2}$

\begin{abstract}
RESUMO
$\mathrm{O}$ artigo apresenta uma reflexão referente à produção científica em educação inclusiva referente ao grupo do Núcleo de Estudos e Pesquisas em Psicopedagogia Diferencial (NEPPD), certificado pelo Conselho Nacional de Desenvolvimento Científico e Tecnológico (CNPQ) no Diretório de Grupos de Pesquisas. O grupo localiza-se na Faculdade de Educação da Universidade Federal do Amazonas (FACED/UFAM) e vem realizando um trabalho interdisciplinar envolvendo estudantes de graduação, pós-graduação e profissionais que atuam na área da educação. Os dados apontam uma intensa produção científica na área, principalmente a partir da publicação da Política Nacional de Educação Especial na Perspectiva da Educação Inclusiva (2008) e do Decreto 7.611/2011. $\mathrm{Na}$ cidade de Manaus/AM, o grupo realiza um trabalho de formação continuada de docentes que atuam nas Secretarias Estaduais e Municipais de Educação. Envolve também estudantes da rede pública por meio de avaliação pedagógica, psicopedagógica e psicomotora, envolvendo inúmeros instrumentos. Portanto, pode-se afirmar que as contribuições integram ações de ensino, pesquisa e extensão, fortalecendo a produção científica na região Amazônica e o estreitamento da relação entre a Universidade e a sociedade amazonense.
\end{abstract}

Palavras-Chave: Pesquisa. Educação Inclusiva. Produção Científica. Extensão Universitária.

\begin{abstract}
The article focuses on production scientific inclusive education for the group Center for Studies and Research in Educational Psychology Differential (NEPPD), certified by the National Council for Scientific and Technological Development $(\mathrm{CNPq})$ Directory of Research Groups. The group is located in the Faculty of Education at the Federal University of Amazonas (FACED / UFAM) and has been conducting interdisciplinary work involving undergraduate students, postgraduate students and professionals working in the field of education. The data show an intense scientific production in the area, mainly from the publication of the National Policy on Special Education in the Perspective of Inclusive Education (2008) and Decree 7.611/2011. In Manaus / AM, the group performs work of continuing education of teachers who work in the Departments of State and Municipal Education. It also involves students from public schools through teacher assessment, psychoeducational and psychomotor, involving numerous instruments. Therefore, it can be stated that the contributions integrate actions of teaching, research and extension, strengthening the scientific production in the Amazon region and strengthening the relationship between the University and the Amazonian society.
\end{abstract}

Keywords: Research. Inclusive Education. Scientific Production. University Extension.

\footnotetext{
${ }^{1}$ Universidade Federal do Amazonas - UFAM. Email: samueljunior.ns@gmail.com

${ }^{2}$ Universidade Federal do Amazonas - UFAM. mail: ketlenjulia4@hotmail.com
} 


\section{INTRODUÇÃO}

O trabalho apresenta um panorama da produção científica do Núcleo de Estudos e Pesquisas em Psicopedagogia Diferencial (NEPPD) e os desafios vivenciados pelos pesquisadores no contexto da execução de projetos de pesquisas e extensão desenvolvidos na UFAM. O NEPPD foi fundado em 2001, por meio da Portaria $n^{0}$ 012/01 da Faculdade de Educação da Universidade Federal do Amazonas (FACED/UFAM). Juntamente com o NEPPD foram fundados diversos grupos de pesquisa tais como o Núcleo de Criatividade e Produção de Imagens, Núcleo de Estudos e Pesquisas em Educação à Distância, Núcleo de Educação Brasileira e Amazônica, e o Grupo Educação, Cultura e Desafios Amazônicos.

Atualmente o grupo vem desempenhando atividades relevantes para a formação de professores do curso de Pedagogia e outras licenciaturas da UFAM, além de contribuir na formação contínua dos profissionais que atuam nas Secretarias Municipais e Estaduais de Educação, bem como na rede privada de ensino da cidade de Manaus. Entende-se que o trabalho interdisciplinar desenvolvido neste grupo deve ser efetuado de forma colaborativa, envolvendo profissionais de várias áreas do conhecimento e proporcionando à comunidade um retorno das ações executadas na Universidade.

Neste artigo são apresentados dados relacionados às pesquisas desenvolvidas no contexto do NEPPD/FACED/UFAM. As ações de pesquisa encontram-se vinculados ao Projeto "Educação Especial, Cidadania, Diversidade e Educação Inclusiva", aprovado em 2009 por meio do Programa de Apoio à Educação Especial, através da Coordenação de Aperfeiçoamento de Pessoal de Nível Superior (PROESP/CAPES). Problematiza-se neste estudo as peculiaridades da região amazônica e a importância do trabalho efetivo desenvolvido por alunos da graduação, pós-graduação, pesquisadores e profissionais da educação e saúde.

Os subprojetos referentes às ações de extensão vinculam-se ao Programa de Apoio Educacional Especializado (PAEE), aprovado em 2011 por meio da Pró-Reitoria de Extensão e Interiorização (PROEXTI). De 2009 a 2013 foram realizados diversos eventos no interior do estado do Amazonas, nas cidades de Coari, Envira, Manacapuru, Manicoré e na capital com vistas à socialização dos conhecimentos produzidos na Universidade, no âmbito da Faculdade de Educação. Contextualizando a UFAM num local estratégico, mesmo que distante de outras regiões do país devido a inúmeros fatores geográficos e econômicos, entende-se a importância desses eventos para a disseminação da produção científica no contexto amazônico. 
A atuação do Núcleo compreende as práticas de pesquisa e de extensão universitária, oferecendo atendimento pedagógico, psicopedagógico e psicomotor às crianças oriundas de escolas públicas das redes municipal e estadual de ensino (MATOS, 2012, 2013). Nesse sentido, são utilizados diversos instrumentos para que seja realizada a avaliação nos contextos pedagógico/psicopedagógico/psicomotor.

Posteriormente é realizado o estudo de caso, onde os pesquisadores reúnem-se para discutir possibilidades de intervenção nas dificuldades de aprendizagem e nos transtornos específicos (dislexia, dislalia, discalculia e disortografia), bem como apoio pedagógico aos educandos com deficiência e transtornos globais do desenvolvimento. O acompanhamento de crianças oriundas das escolas públicas e privadas de Manaus compreende diversas abordagens teórico-metodológicas que vão de encontro com a visão de mundo e a formação dos profissionais envolvidos.

É nesse contexto que o presente trabalho apresenta algumas destas práticas e os inúmeros projetos que interligam-se às ações de pesquisa e extensão exercidas dentro e fora da Universidade. $\mathrm{O}$ artigo traz a discussão sobre a problemática de pesquisas ainda recentes na área de educação inclusiva e da implementação das políticas públicas de inclusão na cidade de Manaus e no restante do Amazonas. Espera-se que o trabalho contribua para a socialização dos conhecimentos produzidos no NEPPD e possa estimular outros alunos da graduação e pós-graduação a debruçarem-se no estudo da realidade amazônica.

\section{A POLÍtica nACIONAL de EDUCAÇÃo ESPECIAL NA PERSPECTIVA DA EDUCAÇÃO INCLUSIVA (2008) E A PRODUÇÃO CIENTÍFICA NA ÁREA}

A atenção educacional aos alunos com necessidades educacionais especiais associadas ou não a deficiência tem se modificado ao longo de processos históricos de transformação social, caracterizando diferentes paradigmas nas relações das sociedades com este segmento populacional (STAINBACK; STAINBACK, 1999; DINIZ, 2007; FÁVERO, 2007; FIGUEIRA, 2011; MANTOAN, 2011). Neste contexto, para a Política Nacional de Educação Especial na Perspectiva da Educação Inclusiva (BRASIL, 2008), este movimento caracterizase como uma ação política, cultural, social e pedagógica, desencadeada pela efetivação do direito de todos à educação.

Partindo disto, é possível verificar no que é exposto a ressignificação do processo de inclusão/exclusão como produtos desta sociedade. A própria Política Nacional de Educação 
Especial na Perspectiva da Educação Inclusiva (2008) aponta que, os sistemas de ensino universalizam o acesso, “[...] mas continuam excluindo indivíduos e grupos considerados fora dos padrões homogeneizadores da escola" (BRASIL, 2008, p. 1). Isto não deixa de ser vinculado ao tipo e modelo de sociedade vigente, reproduzindo aspectos negativos e práticas discriminatórias.

A Política Nacional de Educação Especial na perspectiva da Educação Inclusiva (2008) traz além do marco teórico (MANZINI, 2006; BAPTISTA; CAIADO; JESUS, 2011; MANTOAN, 2011), os objetivos para seu cumprimento e implementação no Brasil a partir dos sistemas de ensino. Visa a garantia da aprendizagem de alunos com deficiência, transtornos globais do desenvolvimento e altas habilidades/superdotação. Orienta os sistemas de ensino para promover respostas às necessidades educacionais especiais, garantindo nas escolas e nos sistemas de ensino:

- Transversalidade da educação especial desde a educação infantil até a educação superior;

- Atendimento Educacional Especializado;

- Continuidade da escolarização nos níveis mais elevados de ensino;

- Formação de professores para o AEE e demais profissionais da educação para a inclusão escolar;

- Participação da família e da comunidade;

- Acessibilidade urbanística, arquitetônica nos mobiliários e equipamentos, nos transportes, na comunicação e informação; e

- Articulação intersetorial na implementação das políticas públicas.

Nesse contexto, a publicação deste documento traz a necessidade de investimento na formação de professores, de adequação na estrutura física/pedagógica das escolas, bem como formação de recursos humanos para atuação no atendimento educacional especializado nas salas regulares de ensino e em outras instituições. É partindo desse pressuposto que o Núcleo realiza suas atividades e propõe a implementação efetiva das políticas inclusivas no contexto regional.

As pesquisas com base nas diretrizes de tal documento (BRASIL, 2008) vêm desenvolvendo-se por meio de inúmeros projetos e programas desenvolvidos em diversas regiões do país. No Amazonas os estudos ainda sã recentes (VINENTE et al 2012) e no Programa de Pós-Graduação da UFAM, a primeira publicação é datada de 1993, antes mesmo da data de criança deste grupo de pesquisa. 
O NEPPD volta seus estudos de iniciação científica para mapeamento das salas de recursos multifuncionais e inclusão escolar na Educação Básica e Ensino Superior a partir de 2008. Tais estudos apontam um cenário novo no que tange ao cumprimento das diretrizes apontadas por diversos documentos que orientam a inclusão escolar de alunos com deficiência na rede pública de ensino.

\section{AS AÇÕES DE PESQUISA DO NÚCLEO DE ESTUdOS E PESQUISAS EM PSICOPEDAGOGIA DIFERENCIAL (NEPPD)}

A pesquisa em educação inclusiva e a socialização dos resultados das mesmas envolvem compromisso social (MATOS, 2008; MENDES, 2011; VINENTE, 2012, 2013) e perpassam os muros da Universidade no sentido de favorecer a implementação de políticas públicas para a inclusão de pessoas com deficiência, transtornos globais do desenvolvimento e altas habilidades e/ou superdotação (BRASIL, 2008; MAGALHÃES, 2011; BAPTISTA, CAIADO, JESUS, 2011; VINENTE, 2012). É nesse contexto que a pesquisa abre horizontes para que repensemos o que está posto na legislação vigente e o que realmente configura-se no cotidiano escolar, tendo em vista os inúmeros desafios que surgem desse processo.

O NEPPD participa desde 2008 de forma efetiva do Programa Institucional de Bolsas para a Iniciação Científica (PIBIC) com 1 projeto em 2008 e 1 projeto em 2009. Em 2010 mais um projeto passa a ser desenvolvido, e em 20113 projetos passam a ser executados com o foco em Autismo, Síndrome de Down e Paralisia Cerebral. Em 2012, esse número continuou, porém a temática de música e educação inclusiva se entrelaçam. No ano de 2013, o Departamento de Apoio à Pesquisa (DAP) aprova 5 novos projetos com as mais variadas temáticas em Educação Inclusiva.

Os resultados parciais e finais desses projetos são socializados em diversos eventos e publicados em anais e periódicos. Abaixo, explicita-se os projetos de pesquisa desenvolvidos desde 2008 que vinculam-se ao projeto CAPES/PROESP citado anteriormente. As temáticas desenvolvidas são as mais variadas e podem ser consultadas no site de coleta e atualização do Diretório dos grupos de Pesquisa do Conselho Nacional de Desenvolvimento Científico e Tecnológico (CNPq). A tabela abaixo traz um panorama das categorias de análise abordadas nas investigações, a agência de fomento que financiou a pesquisa, apresentando as iniciais dos pesquisadores envolvidos e o período de execução dos estudos: 
Rev. Triang. v. 7, n. 2: 78-92, jul./dez. 2014 83

\begin{tabular}{|c|c|c|c|}
\hline Categorias de Análise & $\begin{array}{c}\text { Agência de } \\
\text { Fomento }\end{array}$ & Bolsista/Voluntário & $\begin{array}{l}\text { Período de } \\
\text { Execução }\end{array}$ \\
\hline $\begin{array}{l}\text { Inclusão; } \quad \text { Necessidades } \\
\text { Especiais e Ensino Superior. }\end{array}$ & FAPEAM & M.L.S & $2008 / 2009$ \\
\hline $\begin{array}{l}\text { Inclusão } \quad \text { Educacional; } \\
\text { Legislação Educacional e } \\
\text { Diretrizes Curriculares. }\end{array}$ & FAPEAM & J.S.N & $2009 / 2010$ \\
\hline $\begin{array}{l}\text { Inclusão } \quad \text { Educacional; } \\
\text { Diretrizes Curriculares e } \\
\text { Formação Docente. }\end{array}$ & $\mathrm{CNPq}$ & J.S.N. & $2010 / 2011$ \\
\hline $\begin{array}{lc}\text { Política } & \text { Educacional; } \\
\text { Paralisia } & \text { Cerebral } \\
\text { Organização Pedagógica. }\end{array}$ & $\mathrm{CNPq}$ & S.V.S.J & $2011 / 2012$ \\
\hline $\begin{array}{l}\text { Política Educacional; } \\
\text { Síndrome de Down e Salas } \\
\text { de Recursos Multifuncionais. }\end{array}$ & FAPEAM & A.S.A & $2011 / 2012$ \\
\hline $\begin{array}{l}\text { Política Educacional; } \\
\text { Autismo e Salas de Recursos } \\
\text { Multifuncionais. }\end{array}$ & $\mathrm{CNPq}$ & G.P.T.S. & $2011 / 2012$ \\
\hline $\begin{array}{l}\text { Música/Movimento; Método } \\
\text { Dalcroze e Educação } \\
\text { Inclusiva. }\end{array}$ & FAPEAM & A.M.M & $2012 / 2013$ \\
\hline $\begin{array}{l}\text { Autismo; Inclusão e Salas de } \\
\text { Recursos Multifuncionais. }\end{array}$ & $\mathrm{CNPq}$ & G.P.T.S & $2012 / 2013$ \\
\hline $\begin{array}{l}\text { Políticas Inclusivas; } \\
\text { Formação Docente e } \\
\text { Paralisia Cerebral. }\end{array}$ & FAPEAM & S.V.S.J & $2012 / 2013$ \\
\hline $\begin{array}{l}\text { Ensino Superior; Letras e } \\
\text { Educação Inclusiva. }\end{array}$ & UFAM & K.J.L.S & $2013 / 2014$ \\
\hline $\begin{array}{l}\text { Políticas Públicas; Educação } \\
\text { Inclusiva e Deficiência }\end{array}$ & UFAM & J.V.N & $2013 / 2014$ \\
\hline $\begin{array}{lr}\text { Produção } & \text { Científica; } \\
\text { Educação } & \text { Especial; } \quad \text { Portal } \\
\text { CAPES } & \\
\end{array}$ & $\mathrm{CNPq}$ & A.M.M & $2013 / 2014$ \\
\hline $\begin{array}{ll}\text { Acessibilidade; } & \text { Ensino } \\
\text { Superior e UFAM } & \end{array}$ & UFAM & D.B.S & $2013 / 2014$ \\
\hline $\begin{array}{l}\text { Educação Inclusiva; Paralisia } \\
\text { Cerebral e Tecnologia } \\
\text { Assistiva. }\end{array}$ & $\mathrm{CNPq}$ & $\mathrm{CNPq}$ & $2013 / 2014$ \\
\hline
\end{tabular}

Tabela 1 - Pesquisas de Iniciação Científica desenvolvidas no período de 2009 a 2013.

Na tabela acima é possível observar 14 projetos de iniciação científica (PIBIC), dos quais 5 estão em desenvolvimento. Nesse contexto, a iniciativa é relevante, pois aproxima os discentes da UFAM da realidade escolar. Sendo assim, "O NEPPD vem contribuindo para a 
formação de profissionais preparados para vencer os desafios enfrentados diariamente dentro e fora da Universidade, possibilitando uma aprendizagem significativa e a vivência da pesquisa no Ensino Superior" (VINENTE, 2012, p. 185).

Em consulta ao Diretório dos Grupos de Pesquisas do Conselho Nacional de Desenvolvimento Científico e Tecnológico (DGP/CNPq), realizou-se um levantamento da produção bibliográfica e técnica dos últimos anos. Até o momento, pode-se observar a publicação de 19 artigos em periódicos, 36 trabalhos em anais de evento, 75 resumos publicados em anais de eventos, 3 livros, 5 capítulos de livros e 4 produções bibliográficas isoladas. A ilustração abaixo ilustra os dados citados:

\begin{tabular}{|lr|c|}
\hline \multicolumn{2}{|l|}{ Produção Bibliográfica } \\
\begin{tabular}{|lr|c|}
\hline & Total \\
\hline Artigos Completos Publicados em Periódicos & $\square$ & 36 \\
\hline Trabalhos Publicados em Anais de Evento & $\square$ & 75 \\
\hline Resumos Publicados em Anais de Eventos & $\square$ & 3 \\
\hline Livros & $\square$ & 5 \\
\hline Capítulos de Livros & $\square$ & 4 \\
\hline Outras & & \\
\hline
\end{tabular}
\end{tabular}

Ilustração 1 - Produção Bibliográfica do Grupo de Pesquisa NEPPD (Fonte: CNPQ, 2013)

Nesse contexto, pode-se dizer que "a universidade deve proporcionar ao aluno a vivência plena das ações de ensino, pesquisa e extensão, tendo em vista o desenvolvimento da ciência e tecnologia no contexto amazônico" (VINENTE, 2012, p. 186). As ações de pesquisa e extensão do NEPPD são vinculadas ao Programa de Pós-Graduação em Educação da UFAM e à Faculdade de Educação (FACED), integrando os cursos de graduação e pós-graduação.

No contexto da produção técnica, que envolve apresentações de trabalhos, assessorias, elaboração de relatórios técnico-científicos e demais trabalhos técnicos, o NEPPD totaliza 80 trabalhos apresentados em forma de pôster e comunicação oral, 17 trabalhos técnicos e 39 outras produções divididas em elaboração de material didático e instrucional, formalização de pareceres, assessorias pedagógicas/psicopedagógicas/psicomotoras, palestras, minicursos, workshops, oficinas e organização de eventos. A figura adiante ilustra a produção técnica do NEPPD nos últimos anos: 


\begin{tabular}{|c|c|c|}
\hline \multicolumn{3}{|l|}{ Produção Técnica } \\
\hline & & Total \\
\hline Apresentaçôes de trabalho & $\square$ & 80 \\
\hline Trabalhos Técnicos & $\square$ & 17 \\
\hline Outras & 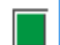 & 39 \\
\hline
\end{tabular}

Ilustração 2 - Produção Técnica do grupo de Pesquisa NEPPD (Fonte: CNPQ, 2013)

A partir dos dados correlacionados é possível visualizar uma produção crescente nos últimos anos. As atividades de pesquisa e extensão que geram essas produções são desenvolvidas por estudantes da graduação e pós-graduação. Em 2011, o primeiro trabalho referente ao atendimento educacional especializado defendido no PPGE/UFAM, em 2013 mais duas dissertações foram defendidas, uma sobre o ensino das artes para alunos com deficiência e outra sobre a inclusão de educandos autistas na rede municipal de ensino da cidade de Manaus.

Até o fim de 2013 serão defendidas mais três dissertações de mestrado e em 2014 será defendida uma tese de doutoramento voltada ao estudo da inclusão da pessoa com deficiência no mercado de trabalho. Este ano, mais cinco projetos vinculados ao PPGE/UFAM estão em desenvolvimento, apresentando resultados preliminares do aprofundamento teóricometodológico da pesquisa. A ilustração abaixo traz um panorama geral das produções técnicas e bibliográficas vinculadas ao NEPPD:

Todas as Produções
\begin{tabular}{|lr|c|}
\hline & Total \\
\hline Trabalhos Publicados em Anais de Evento & $\square$ & 36 \\
\hline Resunnos Publicados em Anais de Eventos & $\square$ & 75 \\
\hline Artigos Completos Publicados em Periódicos & $\square$ & 19 \\
\hline Livro ou Capítulo & $\square$ & 8 \\
\hline Apresentaçôes de trabalho & $\square$ & 80 \\
\hline Trabalhos Técnicos & $\square$ & 17 \\
\hline Outras & $\square$ & 105 \\
\hline
\end{tabular}


Ilustração 3 - Produção Total do grupo de Pesquisa NEPPD (Fonte: CNPQ, 2013)

$\mathrm{Na}$ tabela a seguir pode-se observar a repercussão dos projetos desenvolvidos pelo NEPPD em eventos regionais, nacionais e internacionais:

\begin{tabular}{|c|c|c|c|}
\hline Nome do Evento & Data & Local & $\begin{array}{l}\text { Modalidade } \\
\text { de } \\
\text { Apresentação }\end{array}$ \\
\hline $\begin{array}{l}\text { XXII SEMAPE - Semana de } \\
\text { Pedagogia da UFAM }\end{array}$ & $\begin{array}{c}27 \text { a } 30 \text { de } \\
\text { março de } 2012\end{array}$ & $\begin{array}{c}\text { Universidade } \\
\text { Federal do } \\
\text { Amazonas - UFAM }\end{array}$ & Pôster \\
\hline $\begin{array}{l}\text { I Conferência Interdisciplinar do } \\
\text { IEAA }\end{array}$ & $\begin{array}{c}22 \text { a } 25 \text { de } \\
\text { maio de } 2012\end{array}$ & $\begin{array}{c}\text { Universidade } \\
\text { Federal do } \\
\text { Amazonas - UFAM }\end{array}$ & $\begin{array}{l}\text { Comunicação } \\
\text { Oral }\end{array}$ \\
\hline $\begin{array}{l}\text { III Congresso Nacional de } \\
\text { Educação Inclusiva }\end{array}$ & $\begin{array}{c}08 \text { a } 10 \text { de } \\
\text { agosto de } 2012\end{array}$ & $\begin{array}{c}\text { Universidade } \\
\text { Federal de Roraima- } \\
\text { UFRR }\end{array}$ & $\begin{array}{l}\text { Comunicação } \\
\text { Oral }\end{array}$ \\
\hline $\begin{array}{l}\text { VI Colóquio Internacional de } \\
\text { Filosofia da Educação }\end{array}$ & $\begin{array}{c}14 \text { a } 17 \text { de } \\
\text { agosto de } 2012\end{array}$ & $\begin{array}{l}\text { Universidade do } \\
\text { Estado do Rio de } \\
\text { Janeiro - UERJ }\end{array}$ & $\begin{array}{l}\text { Comunicação } \\
\text { Oral }\end{array}$ \\
\hline $\begin{array}{l}\text { III Simpósio do Autismo no } \\
\text { Contexto da Inclusão }\end{array}$ & $\begin{array}{c}29 \text { a } 31 \text { de } \\
\text { agosto de } 2012\end{array}$ & $\begin{array}{c}\text { Universidade } \\
\text { Federal do } \\
\text { Amazonas - UFAM }\end{array}$ & $\begin{array}{l}\text { Comunicação } \\
\text { Oral }\end{array}$ \\
\hline $\begin{array}{l}2^{\circ} \text { SECAM - Simpósio de } \\
\text { Educação em Ciências na } \\
\text { Amazônia }\end{array}$ & $\begin{array}{c}19 \text { a } 21 \text { de } \\
\text { setembro de } \\
2012\end{array}$ & $\begin{array}{c}\text { Universidade do } \\
\text { Estado do Amazonas } \\
\text { - UEA }\end{array}$ & Pôster \\
\hline $11^{\circ}$ Jornada de Educação Especial & $\begin{array}{c}11 \text { a } 13 \text { de } \\
\text { setembro de } \\
2012 \\
\end{array}$ & $\begin{array}{c}\text { Universidade } \\
\text { Estadual Paulista - } \\
\text { UNESP }\end{array}$ & $\begin{array}{l}\text { Comunicação } \\
\text { Oral }\end{array}$ \\
\hline $\begin{array}{l}\text { IV Seminário Regional de Política } \\
\text { e Administração da Educação }\end{array}$ & $\begin{array}{c}20 \text { a } 22 \text { de } \\
\text { setembro de } \\
2012 \\
\end{array}$ & $\begin{array}{c}\text { Universidade } \\
\text { Federal do Oeste do } \\
\text { Pará - UFOPA } \\
\end{array}$ & $\begin{array}{l}\text { Comunicação } \\
\text { Oral }\end{array}$ \\
\hline $\begin{array}{l}\text { V CBEE - Congresso Brasileiro de } \\
\text { Educação Especial }\end{array}$ & $\begin{array}{c}14 \text { a } 17 \text { de } \\
\text { novembro de } \\
2012 \\
\end{array}$ & $\begin{array}{c}\text { Universidade } \\
\text { Federal de São } \\
\text { Carlos - UFSCar }\end{array}$ & $\begin{array}{l}\text { Comunicação } \\
\text { Oral }\end{array}$ \\
\hline $\begin{array}{c}\text { XIII SEINPE- Seminário } \\
\text { Interdisciplinar de Pesquisa em } \\
\text { Educação }\end{array}$ & $\begin{array}{c}11 \text { a } 13 \text { de } \\
\text { dezembro de } \\
2012\end{array}$ & $\begin{array}{l}\text { Secretaria Municipal } \\
\text { de Educação - } \\
\text { SEMED/AM }\end{array}$ & $\begin{array}{l}\text { Comunicação } \\
\text { Oral }\end{array}$ \\
\hline $\begin{array}{l}\text { IV Congresso Internacional de } \\
\text { Dislexia }\end{array}$ & $\begin{array}{c}09 \text { a } 11 \text { de } \\
\text { maio de } 2013\end{array}$ & $\begin{array}{l}\text { UNESP } \\
\text { Marília/SP }\end{array}$ & Pôster \\
\hline $\begin{array}{l}\text { III Seminário Internacional } \\
\text { Inclusão em Educação }\end{array}$ & $\begin{array}{l}13 \text { a } 15 \text { de } \\
\text { maio de } 2013\end{array}$ & $\begin{array}{l}\text { Universidade } \\
\text { Federal do Rio de } \\
\text { Janeiro }\end{array}$ & $\begin{array}{l}\text { Comunicação } \\
\text { Oral }\end{array}$ \\
\hline $\begin{array}{l}\text { V Seminário Brasileiro de Estudos } \\
\text { Culturais e Educação }\end{array}$ & $\begin{array}{c}20 \text { a } 22 \text { de } \\
\text { maio de } 2013\end{array}$ & $\begin{array}{c}\text { Canoas } \\
\text { ULBRA (RS) }\end{array}$ & $\begin{array}{c}\text { Comunicação } \\
\text { Oral }\end{array}$ \\
\hline $\begin{array}{c}1^{\mathrm{o}} \text { Congresso dos Estudantes de } \\
\text { Pedagogia da UFAM }\end{array}$ & $\begin{array}{c}05 \text { a } 07 \text { de } \\
\text { junho de } 2013\end{array}$ & $\begin{array}{c}\text { Manaus/AM } \\
\text { Universidade } \\
\text { Federal do } \\
\end{array}$ & $\begin{array}{l}\text { Comunicação } \\
\text { Oral }\end{array}$ \\
\hline
\end{tabular}


Tabela 2 - Participação dos pesquisadores do NEPPD em eventos científicos (MATOS, VINENTE, 2012)

\section{O NÚCLEO DE ESTUDOS E PESQUISAS EM PSICOPEDAGOGIA DIFERENCIAL (NEPPD) E A EXTENSÃO UNIVERSITÁRIA NA UFAM}

A extensão universitária é compreendida como um dos eixos que compõem o tripé Ensino-Pesquisa-Extensão, sendo de tal forma relevante para a comunidade na qual a Universidade insere-se, bem como na formação dos discentes e docentes que integram a graduação/pós-graduação na Universidade. O Plano Nacional de Extensão Universitária resgata a definição de extensão defendida no Fórum de Pró-Reitores de Extensão realizado no fim da década de 1980.

Posteriormente, Manaus sedia o Fórum dos Pró-reitores de Extensão das Universidades Públicas Brasileiras. Nesse sentido, tal definição afirma que:

A Extensão Universitária é o processo educativo, cultural e científico que articula o Ensino e a Pesquisa de forma indissociável e viabiliza a relação transformadora entre universidade e sociedade. A Extensão é uma via de mão dupla, com trânsito assegurado à comunidade acadêmica, que encontrará, na sociedade, a oportunidade de elaboração da práxis de um conhecimento acadêmico. [...] Além de instrumentalizadora desse processo dialético de teoria/prática, a Extensão é um trabalho interdisciplinar que favorece a visão integrada do social. (2012, p. 2)

Partindo disto, os pesquisadores do Núcleo de Estudos e Pesquisas em Psicopedagogia Diferencial (NEPPD) entendem que a sociedade é quem mais deve beneficiar-se das ações que resultam da produção do conhecimento da Universidade. Nesse contexto, inúmeros projetos foram desenvolvidos desde 2010, bem como outros estão em andamento e apresentam resultados relevantes para a contribuição na melhoria de vida dos comunitários e na formação dos estudantes da graduação em Pedagogia, Letras-Língua Portuguesa, Música, Psicologia e outros cursos de licenciatura da UFAM. Dentre tais ações podemos citar: 


\section{Programa de Apoio Educacional Especializado (PAEE/NEPPD)}

Este programa engloba diversas atividades de extensão desenvolvidas pelo NEPPD. Foi aprovado em 2011, pela Câmara de Extensão da Pró-Reitoria de Extensão e Interiorização (CEI/PROEXTI/UFAM). Atualmente os projetos e eventos realizados pelo Núcleo vinculamse a esse Programa. Objetiva-se por meio disto apoiar a inclusão de crianças com necessidades educacionais especiais na escola regular, bem como oferecimento do atendimento educacional especializado, formação de professores por meio de congressos e eventos, além de apoio à comunidade.

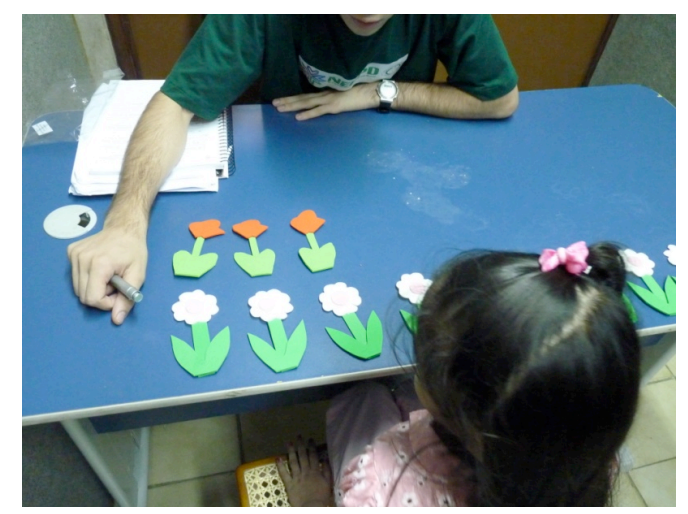

Ilustração 1 - Avaliação e Intervenção psicopedagógica em criança atendida no NEPPD

\section{Programa de Apoio à Realização de Eventos Científicos (PAREV)}

O PAREV objetiva apoiar a realização de cursos e eventos realizados pela Universidade Federal do Amazonas, sendo o referido programa promovido pela Pró-Reitoria de Extensão e Interiorização (PROEXTI). De acordo com as possibilidades orçamentárias são concedidos cartazes, certificados, faixas, pastas, canetas, passagens aéreas, folders, banners e outros materiais aos organizadores e participantes dos cursos e eventos.

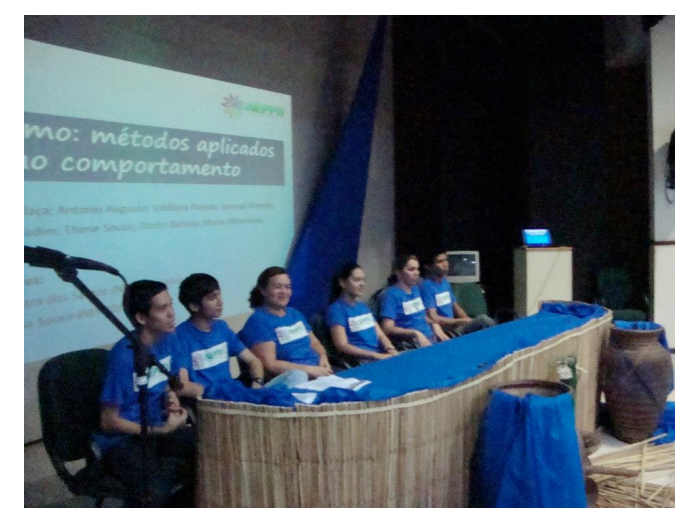

Ilustração 2 - III Simpósio do Autismo no Contexto da Inclusão (2012) 
Desde 2009, o Núcleo realiza o Simpósio do Autismo no Contexto da Inclusão, que em 2014 estará em sua quarta edição, e o Encontro Amazônico de Psicopedagogia, evento este que em 2013 encontra-se em sua terceira edição, realizado simultaneamente ao Encontro Internacional de psicopedagogia. Em suas últimas edições esses eventos científicos congregaram um público com aproximadamente 500 participantes ouvintes, onde inúmeros trabalhos foram socializados.

Programa de Atividade Curricular de Extensão (PACE)

O PACE está vinculado à Pró-Reitoria de Extensão e Interiorização da UFAM, objetivando Intensificar o vínculo que une Universidade e demais segmentos da sociedade, de modo que aquela desempenhe o papel reflexivo e transformador que the cabe no interior desta. Atualmente os projetos desenvolvidas pelo NEPPD tornaram-se ações contínuas que são realizadas simultaneamente na UFAM, numa Obra Social e numa escola pública. Dentre esses projetos, podemos citar:

- A música como instrumento para promoção da inclusão de crianças com necessidades educacionais especiais em atendimento no NEPPD;

- NEPPD e Casa Mamãe Margarida: uma parceria de colaboração psicopedagógica;

- Atendimento Educacional Especializado: uma parceria de apoio pedagógico entre NEPPD e EMEF Firma na Fé;

- Atendimento Educacional Especializado para a comunidade nas salas de avaliação/intervenção do NEPPD/FACED/UFAM.

Atualmente, os pesquisadores do Núcleo de Estudos e Pesquisas em Psicopedagogia Diferencial estão realizando avaliação pedagógica/psicopedagógica/psicomotora em 36 crianças, entre 4 e 12 anos, com encaminhamento de vários profissionais. O Núcleo vem se tornando referência no que se refere ao apoio interdisciplinar prestado à comunidade escolar, envolvendo pedagogos, psicopedagogos, psicólogos, e estudantes da graduação e pósgraduação.

Espera-se o trabalho cresça cada vez mais e abra espaço para que mais pesquisas e projetos de extensão sejam desenvolvidos na Região Amazônica, fomentando e estimulando a produção científica e a melhoria de vida da população com deficiência, transtornos globais do desenvolvimento e dificuldades de aprendizagem. 


\section{CONSIDERAÇÕES FINAIS}

O Núcleo de Estudos e Pesquisas em Psicopedagogia Diferencial (NEPPD) ao decorrer de 12 anos vem contribuindo para a produção de estudos, projetos de ações e pesquisas que permitem os estudantes do curso de Licenciatura Plena em Pedagogia a desempenharem apoio educacional especializado aos estudantes de rede pública de ensino.

O Apoio Educacional Especializado foi regulamentado no ano de 2011 por meio do Decreto $\mathrm{n}^{\circ}$ 7.611, que dispõe no Art $8^{\circ}$, que “o atendimento educacional especializado aos estudantes da rede pública de ensino regular poderá ser oferecido pelos sistemas públicos de ensino ou por instituições comunitárias, confessionais ou filantrópicas sem fins lucrativos $[\ldots] "$

A intervenção psicopedagógica prevista pelo NEPPD para a escola inclui atividades de psicomotricidade para o desenvolvimento global dos educandos, atividades pedagógicas que exercitem a efetividade para o desenvolvimento da autoestima e a orientação familiar. Essa ação de extensão se baseia em adaptações curriculares, ações de apoio específico e inclui atividades individuais e em grupo, objetivando o sucesso na aprendizagem e a melhoria da qualidade de vida dos educandos com necessidades educacionais especiais, fornecendo subsídios necessários para a sociabilidade no seu cotidiano em diferentes situações.

Quanto aos resultados os projetos possibilitaram às crianças com necessidades educacionais especiais o contato com a atividade musical com destaque para o desenvolvimento de suas habilidades através das atividades utilizando a bandinha rítmica mostrando o desenvolvimento motor nas tarefas envolvendo a percepção de diferentes ritmos, além de maior socialização durante as atividades em grupos.

Os dados apontam a necessidade de mais investimento na produção bibliográfica, principalmente em livros, capítulos de livros e periódicos. Porém, entende-se que o grupo de pesquisa vem contribuindo com o crescimento da pesquisa em educação especial na perspectiva da Educação inclusiva no norte do país (BRASIL, 2008, 2011), contribuindo com a comunidade e com a formação dos estudantes da Universidade Federal do Amazonas. Espera-se que os resultados destas ações tragam inúmeros benefícios à população amazonense, fomentando a produção científica em Manaus e no interior do estado. 


\section{REFERÊNCIAS}

BAPTISTA, Cláudio Roberto. Inclusão escolar: políticas municipais de educação e pesquisa. In: MAGALHÃES, Rita de Cássia Barbosa Paiva. Educação Inclusiva: escolarização, política e formação docente. Brasília: Líber Livro, 2011.

BRASIL. Constituição da República Federativa do Brasil. Brasil, 1988.

. LDB: Lei de Diretrizes e Bases da Educação Nacional: Lei n 9394, de 20 de dezembro de 1996. 5. ed. Brasília: Edições Câmara, 2010.

- Plano Nacional de Extensão Universitária 2012. Disponível em: < http://www.renex.org.br/documentos/Colecao-Extensao-Universitaria/01-Plano-NacionalExtensao/Plano-nacional-de-extensao-universitaria-editado.pdf $>$. Acesso em: 20 ago 2013. . Política Nacional de Educação Especial na Perspectiva da Educação Inclusiva. Brasília: MEC/SEESP, 2008.

. Decreto $n^{\circ} 7.611 / 2011$, de 17 de novembro de 2011: dispõe sobre a Educação Especial, o Atendimento Educacional Especializado e dá outras providências. Brasília: Senado Federal, 2011.

CURY, Carlos Roberto Jamil. A educação básica como direito. Cadernos de Pesquisa, v. 38, n. 134, p. 293-303, maio/ago. 2008.

, Carlos Roberto Jamil. Educação e contradição: elementos metodológicos para uma teoria crítica do fenômeno educativo. São Paulo: Autores Associados, 1987.

DINIZ, Debora. O que é deficiência. São Paulo: Brasiliense, 2007.

FÁVERO, Eugênia Augusta Gonzaga. O direito a uma educação inclusiva. In: GUGEL, Maria Aparecida Gugel; COSTA FILHO, Waldir Macieira da; RIBEIRO, Lauro Luiz Gomes (orgs.). Deficiência no Brasil: uma abordagem integral dos direitos das pessoas com deficiência. Florianópolis: Obra Jurídica, 2007.p. 89-109.

MANTOAN, Maria Tereza Eglér (Org.). O desafio das diferenças nas escolas. 4. ed. Petrópolis, RJ: Vozes, 2011.

MATOS, Maria Almerinda de Souza. Cidadania, diversidade e educação inclusiva: um diálogo entre a teoria e a prática na rede pública municipal de Manaus. Tese de Doutorado. Programa de Pós-Graduação em Educação da Universidade Federal do Rio Grande do Sul. Porto Alegre: Faculdade de Educação, 2008. 
, Maria Almerinda de Souza (Org.). Educação especial, políticas públicas e inclusão: desafios da prática e contribuições da pesquisa no NEPPD/FACED/UFAM. Manaus: Vitória, 2012. p. 185-209.

, Maria Almerinda de Souza. Cidadania, Diversidade e Educação inclusiva: um diálogo entre a teoria e a prática na escola pública. Manaus: EDUA, 2013.

MENDES, Enicéia Gonçalves. A formação do professor e a política nacional de educação especial. In: CAIADO, Katia Regina Moreno; JESUS, Denise Meyrelles de; BAPTISTA, Claudio Roberto. Professores e educação especial: formação em foco. Porto Alegre: Mediação, 2011.p. 131-159.

STAINBACK, Susan; STAINBACK, William. Inclusão: um guia para educadores. Tradução: Magda França Lopes. Porto Alegre: Artes Médicas Sul, 1999.

VINENTE, Samuel. O atendimento escolar do aluno com Paralisia Cerebral na rede municipal de ensino em Manaus: a práxis pedagógica n contexto da diversidade. In: MATOS, Maria Almerinda de Souza. Educação especial, políticas públicas e inclusão: desafios da prática e contribuições da pesquisa no NEPPD/FACED/UFAM. Manaus: Vitória, 2012. p. 185-209.

. Samuel et al; Acessibilidade nas escolas municipais da cidade de Manaus: inclusão atitudinal e estrutural do educando com paralisia cerebral. In: III Seminário internacional Inclusão em Educação. 2013. Universidade Federal do Rio de janeiro. Anais. Rio de Janeiro: EDUFRJ, 2013.

RECEBIDO EM: 30/09/2013.

APROVADO EM: 25/09/2015. 